\section{Agricultura ilustrada}

Fernando Antonio LOURENÇO, Agricultura ilustrada: liberalismo e escravismo nas origens da questão agrária brasileira. Campinas, Editora da Unicamp, 2001. 223 páginas.

\section{Pedro Meira Monteiro}

Causará porventura estranheza a combinação, num mesmo texto, de autores como Adorno, Foucault, Marx, Kafka ou Machado de Assis, associados, não sem poucas e devidas mediações, às falas ilustradas de Silvestre Pinheiro Ferreira, do bispo Azeredo Coutinho, de Hipólito da Costa, Evaristo da Veiga, Januário da Cunha Barbosa, Cunha Matos, Frederico Burlamaque, do positivista Pereira Barreto, ou ainda, muito antes, do morgado de Mateus. Causará estranheza, é verdade, mas é da estranheza, ou do estranhamento, que parece nascer a força do livro de Fernando Antonio Lourenço, Agricultura ilustrada: liberalismo e escravismo nas origens da questão agrária brasileira.

Estranhamento diante das fórmulas, não apenas daquelas sociológicas que ele recusa (o livro parece escrever-se contra a "ossificação da Sociologia”), mas também diante das fórmulas liberais que ele destrinça e confronta num processo de delicado e poderoso esclarecimento, pela via da compreensão, isto é, da análise das fontes.

O autor parte de uma distinção convencional entre questão agrária (a dimensão social) e questão agrícola (a dimensão técnica), para constatar ecoando uma recorrente crítica às iniciativas de melhoramento do campo - que no Brasil o agrícola sempre foi priorizado, em detrimento do social. Mas o anúncio, no prefácio e no próprio título, de um estudo de Sociologia rural, poderá levar o leitor a enganar-se. Não se trata apenas de uma investigação sobre o rural. Ou antes, ao debruçarse sobre o discurso ilustrado dos arautos das novas e velhas agriculturas, é a condição humana relativizada, atenuada, finalmente apagada - que interessa a Fernando Lourenço. Por isso, aliás, a intervenção tão própria da Literatura: inicia-se a aventura crítica com um conto de Machado de As- sis, em que se desentranham as características humanas do próprio corpo do homem, reduzido, depois de uma operação científica, à sua condição de ferramenta.

A parábola machadiana, anunciando os horrores das colônias penais (de Kafka à literatura concentracionista), oferece uma espécie de mote, ou mesmo de fio que o autor desenrola, e que o leitor seguirá, atônito, temendo perder-se no labirinto de violência que as fontes mal disfarçam. Leiam-se, por exemplo, as primeiras das medidas governamentais que pontificava o conselheiro Nabuco de Araújo, diante da abolição já inevitável, e incômoda:

$1^{a}$ Obrigar os libertos a engajarem seus serviços dentro de um certo prazo ou com seu antigo senhor ou com outro de sua escolha sob a pena de ser havido por vagabundo. $2^{\text {a }}$ Punir os vagabundos e vadios, não com a prisão simples, que é o que eles desejam, mas com o trabalho nos estabelecimentos ou Colônias disciplinares. $3^{\mathrm{a}}$ Criar esses estabelecimentos e colônias [...].

É um caso extremo, está bem, mas pode-se dizer, desenvolvendo as sugestões de Fernando Lourenço, que o módulo desumanizador desta literatura social ou técnica permanece, como um fantasma indesejado, espreitando cada discurso ilustrado sobre a agricultura, isto é, sobre os campos e os homens e mulheres que neles habitam e trabalham. Daí o caráter um pouco atemporal da análise presente nesta Agricultura ilustrada, que pode se dar ao direito de percorrer transversalmente mais de cem anos de história, da segunda metade do século XVIII ao século XIX (quando se discute tão intensamente a escravidão), e deste ao início do século XX, quando, mais do que nunca, patenteia-se que a simples abolição não significou, antes pelo contrário, a emancipação do trabalhador. O caráter atemporal não deve, entretanto, confundir-se com alguma sorte de anacronismo, mas, bem diferentemente, pode lembrar-nos, a cada nova passagem e análise, a expressão lapidar de Habermas em estudo sobre Benjamin, qual seja, a "permanência do intolerável" no curso da história humana.

O percurso é esclarecedor, tendo como ponto de partida - além da alegoria machadiana da 
ciência moderna - os discursos de alguns dos revolucionários franceses, apresentados em sua flagrante contradição, ou mal dissimulada impotência: desenham-se os direitos civis, mas a questão da igualdade permanece incomodativa e irresolvida, porque é do fundamento da sociedade burguesa a exploração do homem pelo homem, por meio da máquina ou da técnica, justamente. Daí se compreende a crítica à sociedade capitalista, capaz de unir, numa aproximação desconcertante, os contra-revolucionários mais empedernidos, como De Bonald e o próprio Marx, já que ambos traçam, com notável eficácia poética, retratos apavorantes da sociedade moderna. Não faltará, é claro, a lembrança de que a proximidade é ela mesma equívoca, já que as promessas de 1789 são recusadas pelo primeiro e enfrentadas em sua complexidade e impossível fatura pelo segundo. O abismo entre a promessa generosa dos revolucionários e a prática econômica que a tudo justifica (até o injustificável) é enfrentado e analisado neste livro numa chave crítica que não esconde sua fonte maior: O capital, de Marx.

Seguindo as pistas oferecidas pelo autor, é o conceito universal de Homem que, no mais das vezes, não se contempla senão como empecilho nos discursos sobre o mundo do trabalho, e isto lá ou cá. Aí, exatamente, desenrolam-se as análises detalhadas sobre a fala ilustrada brasileira ou luso-brasileira, mediante a qual se introduz a espinhosa questão da subordinação da cidadania (senão da condição humana) à condição de trabalhador. Ao tornar-se homem apenas quando trabalha, sujeitando-se à dignificação (no nível ideológico) e à espoliação (no nível econômico) do processo produtivo, o homem se torna, numa brutal inversão, escravo, ainda que sua condição liberta anuncie o contrário. O que seria a emancipação pelo trabalho converte-se em sujeição, num momento em que a universal condição humana revela sua impotência como força normativa, mostrando-se como mera idéia que empalidece diante da realidade. E a realidade do trabalho, como lembra o autor, apoiado em Marx, Engels e Foucault, jamais andará tão distante do terror das workhouses em que, como na prisão moderna, executa-se a "morte civil" do trabalhador. Interessante que os retratos de Herbert Smith sobre as casas de salga no Rio Grande do Sul, ou de Engels sobre as casas de terror na Inglaterra, sejam aproximados como prenúncio de uma verdade - a da exploração extrema do trabalhador e de sua extenuação não apenas física, mas simbólica - que pulsa sob as fontes, embora Fernando Lourenço não descure da produção historiográfica mais recente sobre o mundo do trabalho no Brasil, lembrando (mas não desenvolvendo) a importância dos "dependentes" como sujeitos que forjam suas estratégias de existência e de reprodução no seio mesmo da dominação senhorial.

Os limites e o alcance, as vicissitudes e os malabarismos das idéias liberais no Brasil são analisados a partir das falas da nossa Ilustração, surgindo com toda a força no sempre surpreendente "liberal-escravismo" de Azeredo Coutinho, na pregação de um governo popular (de que significativamente se exclui a torpe "populaça") de Hipólito da Costa, na "razão aristocrática" dos constituintes de 1823, ou nas amplas justificativas do voto censitário e do governo ilustrado que perpassam os debates parlamentares no Brasil, século XIX adentro.

Por seu turno, as diligências do morgado de Mateus, governador da capitania de São Paulo em tempos pombalinos, expõem, em meio à preocupação de "governamentalizar" o Estado, a identificação dos males da agricultura não apenas nos métodos extenuativos dos solos, mas também na figura do rurícola "indolente", em grande parte culpabilizado pelo atraso econômico que se queria vencer. Verdade que logo reconhecemos a profundidade do diagnóstico ilustrado, capaz de perceber a ação deletéria dos métodos extensivos de cultivo, inferindo, entretanto, o perigo da formação de uma classe de homens volantes, distantes dos centros civilizados (inferência de que não se exclui a crítica da escravidão e dos próprios escravos).

O leitor percorrerá ainda as interessantes páginas sobre a Sociedade Auxiliadora da Indústria Nacional e seu jornal, no qual o melhoramento agrícola propugnado parecia encontrar, amiúde, a resistência de uns lavradores pouco afeitos à ordenação tecnológica da produção, mormente quando "forças africanas" se fizessem presentes... 
Aí se verá o brigadeiro Cunha Matos a sugerir o "adoçamento" das relações entre escravos e seus senhores, não sem propor, como fariam tantos homens de "luzes" nos anos subseqüentes, a desafricanização do país. Frederico Burlamaque, por exemplo, antiescravista convicto, não deixará de propor formas sofisticadas, economicamente eficazes, para extrair o cancro da "raça inimiga" e substituí-la por gente morigerada e operosa, anunciando assim as políticas de imigração do século, ou mesmo as escolas agrícolas que ilustrados mais tardios proporiam como "viveiros de excelentes operários", conforme as diretrizes expostas em periódicos mais novos, como (entre os muitos jornais pesquisados) o Boletim da Agricultura ou o Jornal do Agricultor, mais ao fim do XIX e início do século XX. Era, enfim, a moralização pelo trabalho que vinha se apresentar às classes perigosas, agora também compostas pelos imigrantes e pelos ex-escravos e seus descendentes.

Há momentos da análise em que, como num lampejo, somos levados a perceber as desconcertantes proximidades entre o discurso ilustrado de nossos antepassados - que em tons diversos desqualifica o trabalhador e ao mesmo tempo pode justificar o sistema de trabalho - e o discurso não menos liberal, aliás neoliberal, com que topamos cotidianamente no senso comum da grande imprensa ou das ruas. A força da máquina econômica é tamanha que nos convencemos, sem grande dificuldade, da justeza até mesmo de suas mais injustas fórmulas. Assim também, um entrecortado diálogo com o presente nos faz mirar as fontes em que descansam alguns dos preconceitos correntios desta nossa sociedade de herança escravista.

Interessante, neste livro, que as análises detalhadas e tópicas das fontes escritas não impeçam, antes condicionem, uma análise horizontal, ampla e clarividente, de certas constantes no quadro de um pensamento social brasileiro, como é, principalmente, o horror à democracia, compreendida como governo das massas ignaras. Talvez aí, neste balanço entre o ponto pequeno e o traço largo da interpretação, possamos perceber um segredo do livro, para o qual é fundamental a fineza da linguagem empregada, capaz de aproximar, sem a violência dos esquemas, autores afastados décadas ou sé- culos no tempo, entretanto irmanados em sua reação mais ou menos incisiva à transformação do trabalhador em cidadão, ou ao simples reconhecimento de sua plena condição humana.

A dissimulação que operam as fontes, escondendo motivos, razões, idiossincrasias e veleidades, é enfrentada pela análise de fôlego do sociólogo, que não pretende, aliás, oferecer ao leitor um quadro do mundo "como ele é", mas, apenas e tão-somente, responder às suas inquietações iniciais sobre a "condição humana", reunindo fragmentos em que os homens - supostamente portadores de sua própria humanidade - são representados em sua feição vária, embora quase sempre "discriminados e condenados a ocupar, na escala humana, um grau muito inferior", como premonitoriamente diziam as personagens de Machado de Assis que dão a chave e a senha de entrada desta Agricultura ilustrada. Ensaio percuciente, capaz de nos fazer reconhecer, por fim, algumas das fontes profundas de nossas mazelas sociais, permitindo entrever, no discurso ilustrado das elites, o surgimento incômodo da questão agrária - mas não só dela, por certo.

\section{PEDRO MEIRA MONTEIRO é professor assistente no Departament of Spanish and Portuguese Languages and Cultures, Princenton University.}

